\title{
Multidimensionalidade da maturidade em gestão de projetos de sistemas de informação
}

\author{
Renato de Oliveira Moraes, M.Sc. \\ FEAD - Faculdade de Estudos Administrativos de Minas Gerais \\ renato.moraes@perceptron.com.br
}

Fernando José Barbin Laurindo, Dr.

Departamento de Engenharia de Produção da Escola Politécnica da USP

fjblau@usp.br

Este artigo apresenta o resultado de um levantamento sobre o grau de formalização dos processos de gestão de projetos descritos no PMBoK (Project Management Body of Knowledge) em organizações que desenvolvem projetos de software. Este grau formalização, apesar não constituírem um modelo de maturidade, foi utilizado como uma medida dos diferentes níveis de maturidade empiricamente observados no contexto de nossa realidade. Os dados coletados foram submetidos a uma análise fatorial que levou a indicação de sete dimensões subjacentes a maturidade das organizações estudadas que possuem grande proximidade a estrutura do PMBoK. A análise de clusters, feita em seguida com o objetivo de agrupar as organizações que possuem um nível de maturidade homogêneo, levou a criação de categorias que não possuem uma estrutura semelhante aos dos modelos de maturidade. Foi observado que os grupos formados não podem ser ordenados, pois não é possível afirmar que um determinado grupo possui maturidade em gestão de projetos superior a outro. $\mathrm{O}$ que muda de um grupo para outro e o perfil desta maturidade. Sendo a maturidade, portanto, um conceito multidimensional, o que muda de um grupo para outro é o perfil destas dimensões.

Palavras-chave: gestão de projetos; maturidade em gestão de projeto; processos de gestão de projetos; projetos de tecnologia de informação

This paper presents the results of a research about the degree of formalization of Information Technology project management process according to PMBoK (Project Management Body of Knowledge) practices. Although this is not a maturity model, it can be used as proxy of different maturity levels empirically observed in the studied Brazilian enterprises. Methodological approach was survey and collected data were submitted to factorial analysis, which indicated seven subjacent dimensions of maturity level, and also to cluster analysis that enabled to create groups with similar level of maturity. These groups, however, do not show the same structure of categories of existent maturity models; they cannot be ranked, since it is not possible to state that a certain group presents "superior" project management maturity than the others. What changes from group to another is the profile of the dimensions of their maturity. Therefore, maturity can be understood as a multidimensional concept.

Keywords: project management; project management maturity; project management processes; information technology projects

\section{Introdução}

O dinamismo do ambiente que as empresas enfrentam na acirrada competição dos mercados atuais, associado à crescente importância da indústria de software e das aplicações de Tecnologia da Informação (TI), aumenta a relevância dos estudos acerca de gestão de projetos, em particular dos projetos de sistemas de informação (SI). Por outro lado, a própria gestão de projetos tem sido objeto de estudo tanto por parte de pesquisadores como de profissionais, em diferentes setores de atividades. 
As diferentes propostas de modelos de maturidade em gestão de projetos são baseadas principalmente no CMM (Capability Maturity Model) e também no PMBoK (Project Management Body of Knowledge). A idéia de maturidade de processos como um padrão de estabilidade, que é refletido na transparência e no grau de formalização destes processos, aparece tanto no CMM como na série ISO 9000.

Os modelos de maturidade em gestão de projetos (McGRATH, 1998; GOLDSMITH, 1997; IBBS e KWAK, 1997 e 2000; FINCHER e LEVIN,1997; REMY,1997; HARTMAN e SKULMOSKI, 1997; SCHLICHTER, 2001), em geral, propõem uma "escada" de evolução da maturidade. Isso pode ser entendido como uma evidente influência do modelo CMM - Capability Maturity Model - sobre esses modelos de maturidade.

Contudo, existem sistemas de gestão da qualidade, como a ISO 15.504 que, ao contrário do CMM, não apontam uma direção única de melhoria. São modelos que trabalham com um conceito multidimensional de maturidade e que reconhecem a conveniência, para uma situação específica, de uma correta e circunstancial combinação destas diferentes maturidades. Assim, parece razoável supor que, ao contrário destes muitos modelos de maturidade em gestão de projetos, esta maturidade talvez seja um conceito multidimensional.

Este artigo visa investigar, através de um survey, as dimensões da maturidade em projetos de empresas que desenvolvem sistemas de informação. Para tanto, neste trabalho, fez-se uso de uma definição de maturidade em gestão de projetos baseada no grau de formalização dos processos de gestão de projetos que estão descritos no PMBoK - Project Management Body of Knowledge. Este conceito, apesar de não se constituir em um modelo formal de maturidade, foi utilizado como uma medida dos diferentes níveis de maturidade empiricamente observados no contexto da realidade estudada.

Moraes (2004), utilizando uma abordagem semelhante, constatou que a maturidade em gestão de projetos de desenvolvimento de software possui duas dimensões: Gestão Interna e Gestão de Terceiros. Contudo, esse trabalho, em seu levantamento de campo, não utilizou todos os processos descritos no PMBoK. Apenas os mais representativos de cada uma das nove áreas do conhecimento em gestão de projetos foram usados.

Os dados coletados por Moraes (2004) foram submetidos a uma análise fatorial que levou a indicação de sete dimensões subjacentes a maturidade das organizações estudadas que possuem grande proximidade a estrutura do $\mathrm{PMBoK}$. Os processos de gestão de tempo e de custo descritos no PMBoK, agruparam-se numa única dimensão. Shenhar (2001), ao caracterizar as diferentes faces do desempenho dos projetos, refere-se à Eficiência do Projeto como uma dimensão de curtíssimo prazo que é composta do grau de cumprimento de metas de prazo e de orçamento. Os dados da amostra (MORAES, 2004) levaram ao agrupamento dos processos de gestão de tempo e de custo descritos no PMBoK em única dimensão durante a análise fatorial. Outro resultado relevante deste procedimento foi o fato dos processos de gestão de recursos humanos se distribuíram dentro das dimensões identificadas, sugerindo que esta área de conhecimento (gestão de $\mathrm{RH}$ ) permeia as demais. Em seguida, foi feita a análise de clusters, com o objetivo de revelar um agrupamento de organizações que possuíssem um nível de maturidade homogêneo. Esta análise levou à criação de quatro categorias que não apresentaram uma estrutura semelhante aos dos modelos de maturidade existentes.

Nos modelos de maturidade mais conhecidos, as categorias, que são definidas a priori, possuem algum tipo de ordenação dos níveis de maturidade, tal com acontece no modelo CMM. Na pesquisa apresentada neste presente artigo, foi observado que os grupos formados não podem ser ordenados, pois não é possível afirmar que um determinado grupo possui maturidade superior a outro em termos de gestão de projetos. O que muda de um grupo para outro é o perfil desta maturidade. Sendo a maturidade, portanto, um conceito multidimensional, o que muda de um grupo para outro é o perfil destas dimensões. 
Assim, este presente estudo, ao fazer um levantamento mais detalhado sobre a maturidade dos processos de gestão de projetos de SI, espera contribuir com o entendimento das dimensões subjacentes à maturidade em gestão de projetos. Assim, a pergunta que este trabalho tenta responder fica formulada desta maneira:

Existem evidências teóricas de que a maturidade em gestão de projetos não pode ser avaliada em uma escala unidimensional?

\section{Maturidade e modelos de maturidade em gestão de projetos}

Um levantamento (McGRATH, 1998) feito com 288 empresas de 7 indústrias (incluindo computadores e equipamentos eletrônicos, autopeças eletrônicas, equipamentos médicos, semicondutores e equipamentos de telecomunicações) que investem mais de US\$ 40 bilhões anualmente em pesquisa e desenvolvimento de novos produtos, levou ao desenvolvimento de um modelo de maturidade de processo de desenvolvimento de produto composto de 32 práticas gerenciais. Este modelo classifica as organizações em 4 estágios de maturidade:

- Informal: ausência de um processo consistente de desenvolvimento de produto;

- Funcional: organização funcional com barreiras entre as áreas funcionais;

- Excelência em Projetos: organização utiliza equipes de projetos interdepartamentais no desenvolvimento de novos produtos, e utilizam algum modelo de ciclo de vida com momentos de tomada de decisões claramente definidos; e

- Excelência em Portfólio: a organização possui um processo integrado de gestão permeando todos os projetos e os coordena com uma estratégia de produto e de desenvolvimento tecnológico eficaz.

Goldsmith (1997) tenta com o CMM/Project Maturity Model conciliar o PMBoK e o CMM. É um modelo específico para projetos de software e voltado para preparação para a certificação profissional

dentro do ambiente do Project Management Institute - PMI.

Ibbs e Kwak (1997 e 2000) desenvolveram o Project Management Process Maturity Model (PM2), também influenciado pelo CMM - utiliza cinco níveis de maturidade - e recorta o conceito de maturidade em função de oito áreas de conhecimento do PMBoK (Gestão da Integração, a nona área, é excluída) e das fases do ciclo de desenvolvimento. A tabela 1 mostra a distribuição das perguntas no instrumento de avaliação deste modelo 
Tabela 1 - Distribuição das 148 perguntas no questionário de avaliação da maturidade no modelo $\mathrm{PM}_{2}$

\begin{tabular}{|c|c|c|c|c|c|c|c|}
\hline \multirow[b]{2}{*}{$\begin{array}{l}\text { Áreas de conhecimento em } \\
\text { Gestão de Projetos }\end{array}$} & \multicolumn{6}{|c|}{ Etapas do ciclo de desenvolvimento } & \multirow[b]{2}{*}{ Total } \\
\hline & 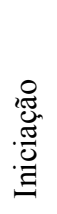 & 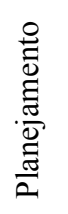 & 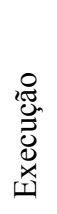 & $\begin{array}{l}\frac{0}{0} \\
\stackrel{\Xi}{\Xi} \\
0 \\
0\end{array}$ & 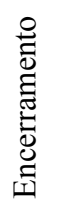 & 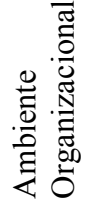 & \\
\hline Escopo & 6 & 7 & 8 & 3 & 3 & 3 & 30 \\
\hline Tempo & 1 & 2 & 12 & 1 & 1 & 1 & 18 \\
\hline Custo & 2 & 2 & 2 & 1 & 1 & 3 & 11 \\
\hline Qualidade & 1 & 2 & 3 & 3 & 3 & 1 & 13 \\
\hline Recursos Humanos & 2 & 4 & 5 & 2 & 2 & 7 & 22 \\
\hline Comunicações & 5 & 3 & 12 & 7 & 2 & 1 & 30 \\
\hline Risco & 1 & 1 & 7 & 6 & 1 & 1 & 17 \\
\hline Aquisição & 1 & 1 & 1 & 1 & 1 & 2 & 7 \\
\hline Total & 19 & 22 & 50 & 24 & 14 & 19 & 148 \\
\hline
\end{tabular}

Também influenciado pelo CMM, o Project Management Maturity Model (PM3) (FINCHER e LEVIN,1997; REMY,1997), ao contrário dos demais, defende a idéia que não é necessário que todas as organizações busquem o nível mais alto de maturidade para serem eficazes. Estes autores sugerem que cada organização deve encontrar a melhor combinação de competências em relação aos seus objetivos.

Hartman e Skulmoski (1997), ao analisarem os modelos de maturidade em gestão de projetos, destacam a necessidade de uma estrutura para o desenvolvimento de modelo universal de maturidade. Esta estrutura deveria contemplar questões técnicas, de negócio e sociais.

O modelo Organizational Project Management Maturity Model (OPM3) é, provavelmente, o que terá maior aceitação pelos profissionais de gestão de projetos. Isto porque seu desenvolvimento tem sido patrocinado pelo PMI, e conta, portanto, com o apoio desta instituição. O grupo que o desenvolve identificou um conjunto de elementos que devem ser avaliados na determinação da maturidade da organização em gestão de projetos (SCHLICHTER, 2001). Estes elementos foram agrupados em dez categorias:

- Padronização e integração de métodos e processos

- Métricas e desempenho

- Comprometimento como processo de gestão de projetos

- Priorização e alinhamento como negócio

- Melhoramento contínuo

- Critérios de sucesso para continuação e interrupção

- Pessoas e suas competências

- Alocação de pessoas a projetos

- Adequação organizacional

- Trabalho em equipe

O conceito de maturidade em gestão e projetos é ligado ao desenvolvimento contínuo de competências especificas em gestão de projetos (KALANTJAKOS, 2001 e SCHLICHTER, 2001), o que sugere a idéia de ser possível estabelecer, de um modo geral, algum tipo de modelo direcionador assim como o PMBoK tem sido. 
Como se pode facilmente notar, os modelos de maturidade em gestão de projetos são fortemente influenciados por outros dois modelos:

- $\mathrm{PMBoK}$ - Project Management Body of Knowledge; e

- CMM - Capability Maturity Model.

O CMM tem fornecido uma estrutura baseada nos níveis de maturidade determinada por processos implantados. O PMBoK traz uma caracterização dos processos de gestão de projetos. A combinação destas duas referências tem dado origem a diferentes propostas de modelos de maturidade de gestão de processos.

O CMMI (Capability Maturity Model Integration) é uma evolução e expansão do CMM e apresenta novos conceitos que não existiam no modelo original. Contudo, a idéia de maturidade em gestão de projetos surgiu antes da publicação do CMMI. Isto fica claro quando se observa os níveis de maturidade em gestão de projetos de alguns dos modelos citados anteriormente (GOLDSMITH, 1997; IBBS e KWAK, 1997 e 2000; REMY, 1997; SCHLICHTER, 2001).

A idéia de maturidade de processos está, portanto, associada ao conceito de estabilidade de processos. Processos estáveis são processos livres de variações e que são executadas de forma consistentemente homogênea. A formalização dos processos reflete esta estabilidade como reflete o bordão do modelo ISO 9.000 "faça o que escreve e escreva o que faz" (ANTONIONI e ROSA, 1995).

Nesta visão, a qualidade de um produto é determinada pela qualidade do processo que o gerou. Assim, a qualidade do processo de desenvolvimento do projeto de software irá condicionar a qualidade do software gerado. Esta é a mesma idéia por trás dos modelos de garantia da qualidade como ISO 9.0003, CMM e ISO 15.504. Nestes modelos a qualidade do processo é obtida pela estabilidade dos processos. Desta forma, quando uma organização inicia sua certificação, os auditores procuram verificar se os processos prescritos nestes modelos existem. Além da existência destes processos, são confrontados os registros destes processos com suas práticas (ANOTINIONI e ROSA, 1995).

Ao contrário dos modelos propostos de maturidade em gestão de projetos comentados anteriormente, não é relevante para o objetivo deste trabalho uma caracterização prévia de níveis de maturidade. Caso fosse aqui adotado algum modelo, existiria a preocupação de construir uma amostra de forma a ter uma quantidade expressiva de indivíduos em cada nível de maturidade. Além desta questão de ordem prática, existe outra de ordem conceitual que se refere à própria validade dos modelos propostos. Eles são ainda muito recentes, não foram satisfatoriamente testados e ainda se encontram em desenvolvimento.

Nesse trabalho, o que importa é o uso de procedimentos que permitam separar os elementos da amostra em grupos homogêneos de maturidade. Portanto, a caracterização prévia destes grupos - que poderia ser obtida pela adoção de um de modelo de maturidade - não é necessária. A caracterização destes grupos será feita após sua formação - por meio de procedimentos estatísticos (análise de clusters, principalmente). A questão relevante então passa a ser a identificação dos processos de gestão de projetos relevantes à avaliação da maturidade nas organizações da amostra. O PMBoK é, por sua relevância e aceitação dentro e fora do país, a resposta a esta questão. Ele traz, agrupados em áreas de conhecimento, os principais processos em gestão de projetos. Desta forma, os processos descritos no PMBoK serão utilizados na avaliação da maturidade das organizações neste trabalho.

\subsection{PMBOK - Project Management Body of Knowledge}

O PMBoK (Project Management Body of Knowledge) é o resultado do esforço do PMI (Project Management Institute) em registrar e documentar uma base de conhecimentos para a atividade de Gestão de Projetos. A primeira versão foi publicada em 1984 e revista em 1987, 1996, 2000 e 2004. Apesar de esforços similares, como os realizados na Suíça e na Austrália, esta parece ser principal referência em vigor com mais de 450.000 exemplares em circulação (CLELAND e IRELAND, 2002). 
Os vários modelos de maturidade em gestão de projetos utilizam o PMBoK, em maior ou menor grau, como referência conceitual.

Faz-se aqui necessária uma explicação do não uso da última versão do PMBoK, publicada em 2004. Este trabalho foi realizado em 2003 quando apenas a segunda edição deste documento estava disponível. Assim, a descrição que se segue está baseada ainda na segunda edição, que foi a que direcionou este estudo.

O PMBoK descreve um conjunto de processos agrupados em áreas de conhecimento, associados com a Gestão de Projetos. O conhecimento necessário ao bom desempenho de um gerente de projeto, como destaca o PMBoK, envolve conhecimentos relacionados à:

- Gerência Geral;

- Conhecimento e práticas específicas da área em que o projeto está sendo desenvolvido (engenharia civil, computação, farmacologia, etc.); e

- Gerência de Projetos.

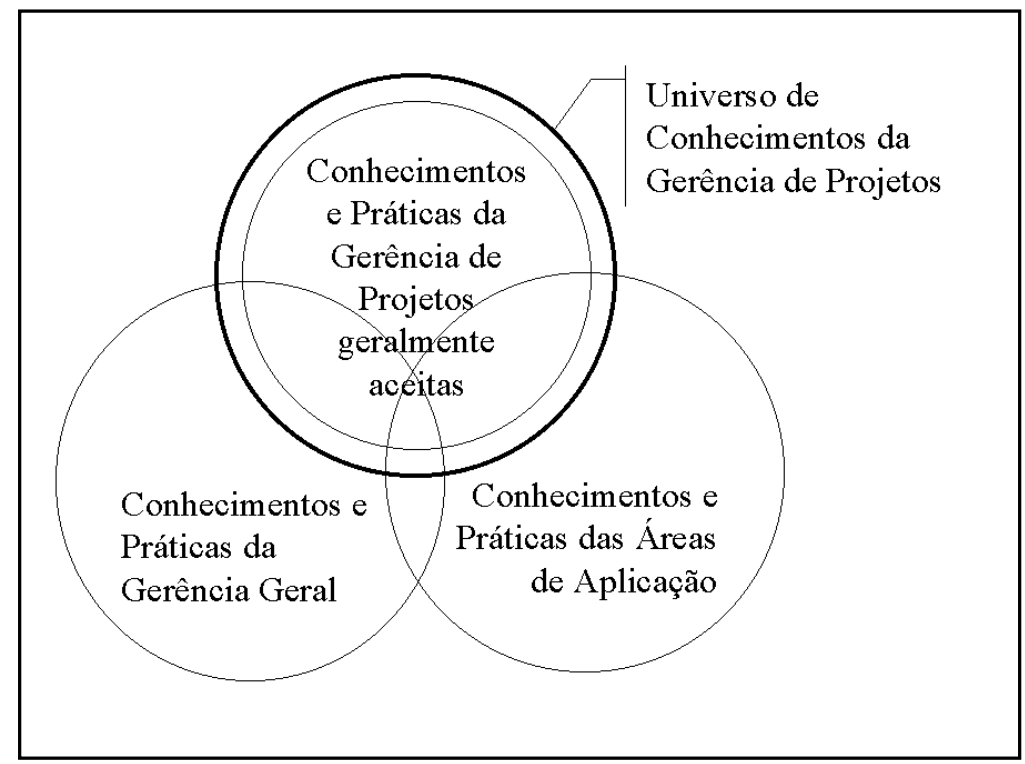

Figura 1 - Disciplinas Gerenciais relacionadas à Gestão de Projetos Fonte: PMBoK (2000)

A compilação destes conhecimentos e práticas geralmente aceitas de Gestão de Projetos gerou o PMBoK. Em função de sua proximidade temática, estes conhecimentos foram agrupados em 9 grandes áreas no PMBoK. O quadro da Figura 2 mostra estas nove áreas e os processos de gestão de cada uma delas: 


\begin{tabular}{|c|c|}
\hline Área de Conhecimento & Processos \\
\hline 1. Gestão da Integração & $\begin{array}{l}\text { Desenvolvimento do Plano do Projeto } \\
\text { Execução do Plano do Projeto } \\
\text { Controle Integrado de Mudanças }\end{array}$ \\
\hline 2. Gestão do Escopo & $\begin{array}{l}\text { Iniciação } \\
\text { Planejamento do Escopo } \\
\text { Detalhamento do Escopo } \\
\text { Verificação do Escopo } \\
\text { Controle de Mudanças de Escopo }\end{array}$ \\
\hline 3. Gestão do Tempo & $\begin{array}{l}\text { Definição das Atividades } \\
\text { Seqüenciamento das Atividades } \\
\text { Estimativa da Duração das Atividades } \\
\text { Desenvolvimento do Cronograma } \\
\text { Controle do Cronograma }\end{array}$ \\
\hline 4. Gestão do Custo & $\begin{array}{l}\text { Planejamento dos Recursos } \\
\text { Estimativa dos Custos } \\
\text { Orçamento dos Custos } \\
\text { Controle dos Custos }\end{array}$ \\
\hline 5. Gestão da Qualidade & $\begin{array}{l}\text { Planejamento da Qualidade } \\
\text { Garantia da Qualidade } \\
\text { Controle da Qualidade }\end{array}$ \\
\hline 6. Gestão dos Recursos Humanos & $\begin{array}{l}\text { Planejamento Organizacional } \\
\text { Montagem da Equipe } \\
\text { Desenvolvimento da Equipe }\end{array}$ \\
\hline 7. Gestão das Comunicações & $\begin{array}{l}\text { Planejamento das Comunicações } \\
\text { Distribuição das Informações } \\
\text { Relato de Desempenho } \\
\text { Encerramento Administrativo }\end{array}$ \\
\hline 8. Gestão dos Riscos & $\begin{array}{l}\text { Planejamento da Gerência de Riscos } \\
\text { Identificação dos Riscos } \\
\text { Análise Qualitativa dos Riscos } \\
\text { Análise Quantitativa dos Riscos } \\
\text { Desenvolvimento de Resposta a Riscos } \\
\text { Controle e Monitoração de Riscos }\end{array}$ \\
\hline 9. Gestão das Aquisições & $\begin{array}{l}\text { Planejamento das Aquisições } \\
\text { Preparação das aquisições } \\
\text { Obtenção das Propostas } \\
\text { Seleção de Fornecedores } \\
\text { Administração de Contratos } \\
\text { Encerramento de Contrato }\end{array}$ \\
\hline
\end{tabular}

Figura 2 - Processos de gestão de projetos

Fonte: PMBoK (2000)

Os processos de gestão podem ser classificados, inclusive, em função do ciclo de vida do projeto. Dessa forma, os processos estão divididos em:

- Processos de iniciação;

- Processos de planejamento;

- Processos de execução;

- Processos de controle; e

- Processos de encerramento.

A maneira pela qual esses grupos de processos se relacionam está ilustrada na Figura 4. O quadro da Figura 3 contém a descrição de cada um desses grupos. 


\begin{tabular}{|ll|}
\hline Processos & Descrição \\
\hline $\begin{array}{l}\text { Processos de } \\
\text { iniciação }\end{array}$ & $\begin{array}{l}\text { Reconhecer que um projeto ou fase deve começar e se comprometer para executá- } \\
\text { lo(a). }\end{array}$ \\
\hline $\begin{array}{l}\text { Processos de } \\
\text { planejamento }\end{array}$ & $\begin{array}{l}\text { Planejar e manter um esquema de trabalho viável para se atingir aqueles objetivos } \\
\text { de negócios que determinaram a existência do projeto. }\end{array}$ \\
\hline $\begin{array}{l}\text { Processos de } \\
\text { execução }\end{array}$ & Coordenar pessoas e outros recursos para realizar o plano. \\
\hline Processos de controle & $\begin{array}{l}\text { Assegurar que os objetivos do projeto estão sendo atingidos, através da } \\
\text { monitoração e da avaliação do seu progresso, tomando ações corretivas quando } \\
\text { necessárias. }\end{array}$ \\
\hline $\begin{array}{l}\text { Processos de } \\
\text { encerramento }\end{array}$ & $\begin{array}{l}\text { Formalizar a aceitação do projeto ou fase e encerrá-lo(a) de uma forma } \\
\text { organizada. }\end{array}$ \\
\hline
\end{tabular}

Figura 3 - Grupos de Processos de Gestão

Fonte: PMBoK (2000)

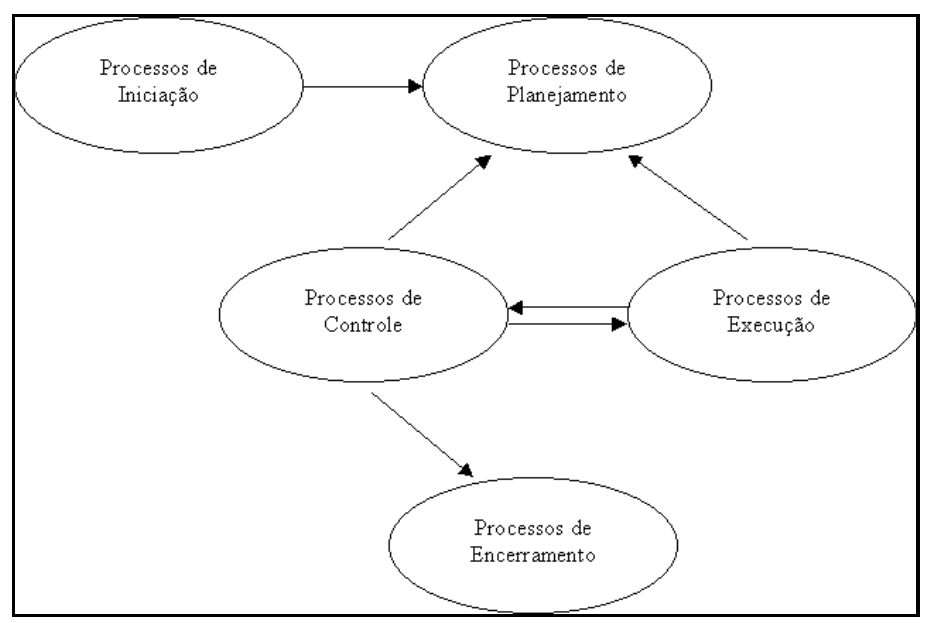

Figura 4 - Ligações entre os grupos de processos

Fonte: PMBoK (2000)

É importante notar a sobreposição temporal desses grupos de processos no ciclo de desenvolvimento do projeto e no desenvolvimento de cada etapa do ciclo. Esta sobreposição está ilustrada na Figura 5.

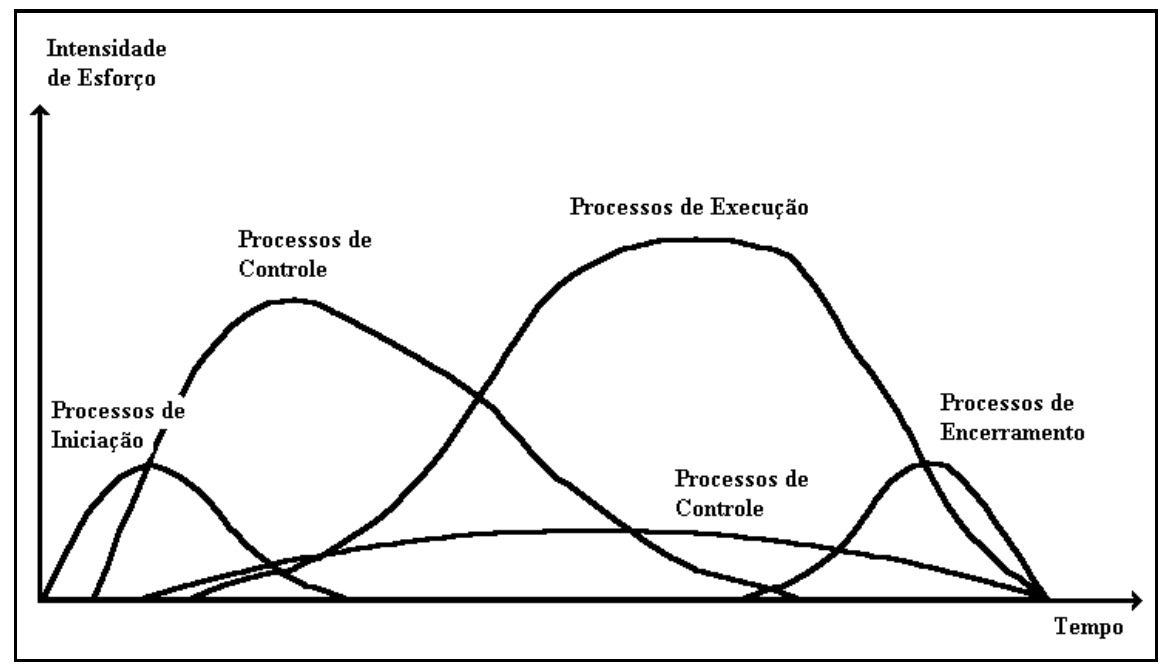

Figura 5 - Execução dos processos no tempo

Fonte: PMBoK (2000) 


\section{Metodologia}

O objetivo deste artigo é investigar as dimensões da maturidade em projetos de empresas que desenvolvem SI. Por sua vez, a pergunta que este trabalho tenta responder é: Existem evidências teóricas de que a maturidade em gestão de projetos não pode ser avaliada em uma escala unidimensional? Para este fim, a metodologia adotada foi a de um survey.

A população da pesquisa é o conjunto de empresas que atuam em desenvolvimento de sistemas de informação computadorizados, mais especificamente, organizações que desenvolvem sistemas de informação para apoio a gestão para uso interno ou externo (por outras empresas). Para atingir estes elementos foi desenvolvido um questionário auto preenchido que foi enviado, via e-mail, para cerca de 1.100 profissionais da área de tecnologia da informação nos estados de São Paulo e Rio de Janeiro. O questionário apresentava os objetivos da pesquisa e solicitava que o destinatário, caso este atendesse certos requisitos (experiência em desenvolvimento de sistemas de informação), respondesse o questionário. Nestas condições, a amostra não é probabilística e sim intencional por conveniência.

Como mostra a Tabela 6, participaram da pesquisa diferentes tipos de organizações e os respondentes têm, em média, 4,5 anos de experiência no cargo de coordenador/supervisor de desenvolvimento de sistemas de informação. Cerca de $62 \%$ dos respondentes atuam no setor de serviços com expressiva participação de consultorias. A grande maioria dos respondentes - aproximadamente $77 \%$ - ocupa cargo de direção ou gerência. Dos questionários enviados, foram devolvidos 101 questionários, mas apenas 98 foram considerados válidos.

\subsection{Análise dos resultados obtidos}

Os dados assim colhidos foram submetidos à análise fatorial para que se pudesse: (1) obter uma redução dimensional do problema e (2) identificar dimensões subjacentes à maturidade em gestão de projetos da forma que foi aqui definida (estabilidade e formalização dos processos de gestão descritos no PMBoK).

O valor do coeficiente KMO (Kaiser-Meyer-Olkin) foi de 0,889 a um nível de significância -de $0,1 \%$, o que indica a adequação da aplicação desta técnica (análise fatorial) aos dados utilizados. Foram extraídos apenas os fatores com eigenvalue maior que um. Estes sete fatores representam 74,4 \% do comportamento de todas as variáveis originais.

Para facilitar a tarefa de interpretação, foi realizada uma rotação ortogonal pelo método varimax. Em função das características das cargas resultantes a denominação dos fatores tornou-se bastante imediata. A Tabela 2 traz o valor destas cargas fatoriais. 
Tabela 2 - Carga Fatorial dos Fatores extraídos

\begin{tabular}{|c|c|c|c|c|c|c|c|}
\hline & \multicolumn{7}{|c|}{ Componente } \\
\hline & 1 & 2 & 3 & 4 & 5 & 6 & 7 \\
\hline Obtenção das Propostas & 793 & ,254 & ,141 & ,109 & ,196 & ,103 & 099 \\
\hline Seleção de Fornecedores & ,770 & ,267 & ,049 & , 190 & ,094 & ,129 & 047 \\
\hline Encerramento de Contrato & ,756 & ,026 & ,179 & ,220 & ,178 & 016 & , 124 \\
\hline Administração de Contratos & 666 & ,000 & ,192 & ,422 & ,249 & , 199 &,- 040 \\
\hline Planejamento das Aquisições & 640 & ,382 & 166 & ,146 & ,265 & ,133 & ,188 \\
\hline Desenvolvimento de Resposta a Riscos & 499 & ,447 & ,322 & ,317 & 179 & ,096 & 144 \\
\hline Estimativa da Duração das Atividades &,- 029 & ,738 & 261 & ,260 & 183 &,- 057 & 105 \\
\hline Controle dos Custos & ,260 & 669 & ,082 &,- 014 & 176 & 325 & 149 \\
\hline Orçamento dos Custos & ,339 & ,665 & ,112 &,- 051 & ,308 & ,305 &,- 123 \\
\hline Estimativa dos Custos & ,172 & ,656 & 147 & 150 & ,323 & 383 & ,068 \\
\hline Planejamento dos Recursos & ,270 & 648 & ,217 & ,267 & 155 & ,038 & 295 \\
\hline Seqüenciamento das Atividades & ,213 &, 546 & ,299 & ,439 & 052 & 020 & , 192 \\
\hline Definição das Atividades & ,233 & ,523 & 297 & 472 & ,092 &,- 101 & 243 \\
\hline Planejamento do Escopo & 306 & 150 & ,768 & ,060 & ,216 &,- 086 & ,089 \\
\hline Detalhamento do Escopo & 046 & ,227 & ,768 & 092 & , 149 & ,137 & ,261 \\
\hline Verificação do Escopo & , 136 & 057 & ,641 & ,250 & ,332 & 067 & ,297 \\
\hline Planejamento Organizacional & 036 & ,392 & 610 & ,302 & , 190 & , 145 & ,056 \\
\hline Iniciação & 498 & ,042 & ,571 & 141 &,- 025 & ,233 & 135 \\
\hline Controle de Mudanças de Escopo & ,234 & 339 & ,525 & 186 & ,303 & 112 & 239 \\
\hline Desenvolvimento do Cronograma & 107 & ,441 & ,524 & 207 &,- 205 & ,305 & 147 \\
\hline Planejamento das Comunicações & ,339 & ,136 & ,177 & ,710 & ,214 & ,272 & , 141 \\
\hline Relato de Desempenho & 344 & 290 & 071 & ,631 & 164 & 308 & 170 \\
\hline Distribuição das Informações & ,374 & ,189 & ,285 & 620 & , 181 & ,228 & , 185 \\
\hline Encerramento Administrativo & 373 & 097 & ,080 & 607 & ,267 & 317 & 171 \\
\hline Montagem da Equipe & ,085 & 287 & 423 & ,544 & 180 & 123 & 128 \\
\hline Desenvolvimento da Equipe & 146 & 140 & 489 & 496 & ,303 & 196 &,- 191 \\
\hline Análise Qualitativa dos Riscos & ,222 & 203 & 174 & ,315 & ,773 & 127 & 134 \\
\hline Identificação dos Riscos & ,230 & 296 & 187 & 192 & ,773 & ,235 & ,072 \\
\hline Análise Quantitativa dos Riscos & 318 & ,346 & 179 & 193 & 648 & ,094 & 294 \\
\hline Planejamento da Gerência de Riscos & ,336 & ,085 & 416 & 191 & 613 & 205 & ,073 \\
\hline Planejamento da Qualidade & , 160 & ,350 & 197 & 133 & ,545 & ,525 & ,097 \\
\hline Garantia da Qualidade & 179 & 202 & ,092 & ,258 & ,213 & ,820 & ,099 \\
\hline Controle da Qualidade & ,150 & ,088 & 177 & ,360 & 183 & ,753 & 172 \\
\hline Execução do Plano do Projeto & 137 & 178 & ,450 & 192 & ,036 & 193 & ,717 \\
\hline Controle Integrado de Mudanças & 119 & ,172 & 181 & ,383 & 227 & 238 & 628 \\
\hline Desenvolvimento do Plano do Projeto & ,242 & ,304 & ,387 & ,000 & ,281 & 022 & ,566 \\
\hline
\end{tabular}

O primeiro fator obtido - Aquisição - contém apenas processos de gestão da aquisição com cargas significativas.

No segundo fator - Eficiência - houve uma concentração dos processos de gestão de tempo e do custo.

No fator 3 - Escopo - estão concentrados todos os processos de gestão do escopo e outros dois processos que estão fortemente relacionados com esta área de conhecimento: Desenvolvimento do Cronograma e Planejamento Organizacional.

No fator 4 - Comunicações - estão todos os processo desta área e um da área de gestão de recursos humanos.

No fator 5 - Riscos - estão todos os processos de gestão de riscos e o processo Planejamento da Qualidade.

No fator 6 - Qualidade - estão todos os processos de gestão da qualidade, e o mesmo acontece no fator 7 - Integração - onde estão todos os processos de gestão da integração.

Dois aspectos destacam-se aqui. Primeiramente, a junção de duas áreas de conhecimento do PMBoK em uma única dimensão da maturidade. Esta união dos processos de gestão do prazo e do tempo pode ser relacionada à visão de desempenho dos projetos no curto prazo - observância a prazos e 
orçamentos. Shenhar (2001), como visto, denomina esta dimensão do desempenho dos projetos como Eficiência do Projeto, que, de certa forma, explica o agrupamento destas duas áreas de conhecimento.

O segundo aspecto de destaque foi "diluição" dos processos de gestão de recursos humanos pelas diversas dimensões identificadas. Isto pode ser interpretado como uma sugestão de que estes processos perpassam e subsidiam os demais processos de gestão de projetos.

Hair et al. (1989) recomendam como mínimo aceitável para uma escala confiável o valor de 0,6 para o Alfa de Cronbach. A Tabela 3 abaixo mostra o valor desta estatística (Alfa de Cronbach) para os fatores extraídos.

Como se pode observar, os valores são bastante satisfatórios indicando a confiabilidade (interna) das escalas geradas na análise fatorial.

Tabela 3 - Comportamento dos fatores extraídos nos grupos formados
\begin{tabular}{|c|c|c|}
\hline Fator & Alfa de Cronbah & Qtde de elementos \\
\hline 1 & 0,904 & 6 \\
\hline 2 & 0,908 & 8 \\
\hline 3 & 0,893 & 8 \\
\hline 4 & 0,907 & 6 \\
\hline 5 & 0,928 & 5 \\
\hline 6 & 0,916 & 2 \\
\hline 7 & 0,819 & 3 \\
\hline
\end{tabular}

Os fatores extraídos e interpretados substituíram as variáveis originais na análise que se seguiu. Foi realizada uma análise de clusters com o objetivo de verificar se o comportamento das organizações da amostra em relação às diferentes dimensões de maturidade em gestão de projetos. Inicialmente, empregou-se um método hierárquico (Método de Ward com distância euclidiana como medida de similaridade) para a determinação do número de clusters a serem formados. O dendograma resultante encontra-se em anexo. A escolha da quantidade de clusters a serem formados, como afirma Hair et al. (1988), tem, freqüentemente, alguma carga de subjetividade. O dendograma, que é apresentado no anexo, poderia indicar para alguns a formação de uma quantidade maior de grupos - seis ou oito. Contudo, a evolução da medida global de dissimilaridade do roteiro de aglomeração sugere também a formação a de 4 grupos. Somam-se a isto as possibilidades de explicação e análise encontradas pelos autores a esta alternativa - 4 grupos - como recomenda Hair et al. (1988).

Escolhida a quantidade de grupos a serem formados (quatro), foi utilizado o método $K$-means para formação dos grupos com o objetivo de maximizar as diferenças entre os grupos. A Tabela 4 mostra as características dos grupos e a Tabela 5 mostra o resultado da análise de variância tendo como variável independente a classificação gerada na análise de clusters (cada um dos quatro grupos) e como variáveis dependentes os fatores extraídos anteriormente

Tabela 4 - Comportamento dos fatores extraídos nos grupos formados

\begin{tabular}{|c|c|c|c|c|c|c|c|c|}
\hline \multirow{2}{*}{ Grupos } & \multirow{2}{*}{$\mathrm{N}$} & \multicolumn{7}{|c|}{ Fatores de maturidade extraídos } \\
\cline { 3 - 9 } & & Aquisições & Eficiência & Escopo & Comunicação & Riscos & Qualidade & Integração \\
\hline 1 & 23 & 0,002 & 1,110 & $-0,662$ & $-0,095$ & 0,102 & 0,324 & $-0,243$ \\
\hline 2 & 40 & 0,117 & $-0,107$ & 0,610 & 0,353 & 0,408 & 0,227 & $-0,020$ \\
\hline 3 & 17 & 0,291 & $-1,019$ & $-0,837$ & $-0,221$ & $-0,354$ & 0,256 & 0,898 \\
\hline 4 & 18 & $-0,537$ & $-0,217$ & 0,281 & $-0,454$ & $-0,704$ & $-1,160$ & $-0,493$ \\
\hline
\end{tabular}




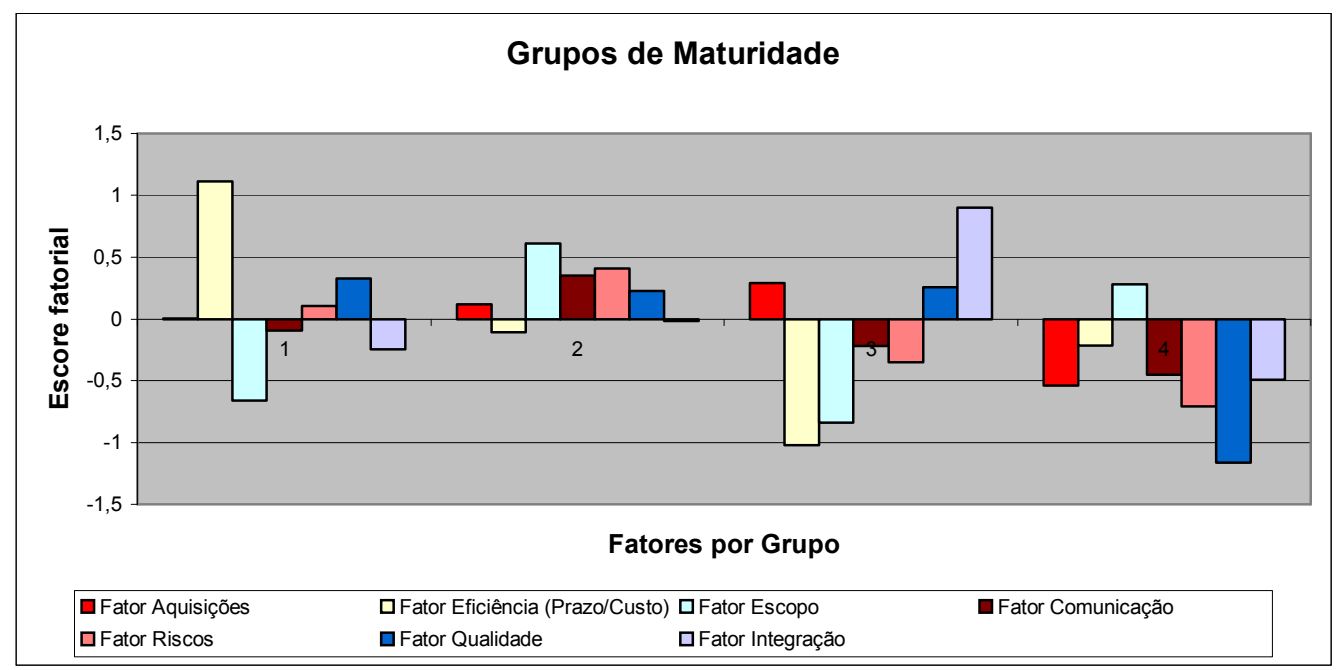

Figura 6 - Perfil dos grupos formados pela análise de clusters

Tabela 5 - Análise de variância - diferenças entre os grupos

\begin{tabular}{|l|r|r|r|r|r|r|}
\hline & \multicolumn{2}{|c|}{ Cluster } & \multicolumn{2}{c|}{ Error } & F & Sig. \\
\hline & Mean Square & df & Mean Square & Df & \\
\hline Fator Aquisições & 2,391 & 3 &, 956 & 94 & 2,503 &, 064 \\
Fator Eficiência (Prazo/Custo) & 15,771 & 3 &, 529 & 94 & 29,836 &, 000 \\
Fator Escopo & 12,762 & 3 &, 625 & 94 & 20,432 &, 000 \\
Fator Comunicação & 3,239 & 3 &, 929 & 94 & 3,488 &, 019 \\
Fator Riscos & 5,981 & 3 &, 841 & 94 & 7,111 &, 000 \\
Fator Qualidade & 9,937 & 3 &, 715 & 94 & 13,903 &, 000 \\
Fator Integração & 6,486 & 3 &, 825 & 94 & 7,862 &, 000 \\
\hline
\end{tabular}

É interessante observar que apenas o Fator Aquisições não apresentou diferenças entre os grupos.

O Fator Eficiência apresenta valor médio maior no grupo 1, seguido pelos grupos 2 e 4 (sem diferenças entre eles) e o grupo 3 apresentou o desempenho mais baixo.

O Fator Escopo mostrou valor médio mais alto nos grupos 2 e 4, e valor médio menor nos grupos 1 e 3.

O Fator Comunicação apresentou diferença apenas entre os grupos 2 e 4, entre os quais não foram observadas diferenças estatisticamente significativas.

No Fator Riscos foi observada diferença entre o grupo 4 os grupos 1 e 2, isto é ,no grupo 4 o escore deste fator (Riscos) é significativamente menor do que nos grupos 1 e 2.

No Fator Qualidade, o grupo 4 está significativamente abaixo dos demais.

No Fator Integração, o grupo 3 está acima dos demais grupos.

O Quadro 3 mostra o resultado da comparação dos fatores dentro de cada grupo. Aqui foi feita uma série de comparações de médias emparelhadas através do Teste $t$.

No grupo 1, os fatores Eficiência (principalmente) e Escopo destacam-se dos demais fatores.

No grupo 2, os fatores Escopo e Eficiência são os que mais se distinguem dos demais.

No grupo 3, os fatores Integração e Eficiência são os que mais apresentam diferenças com os demais fatores. 
No grupo 4, os fatores Escopo (principalmente) e Qualidade são os que mais apresentam diferenças com os demais fatores.

Quadro 3 - Comparação de médias emparelhadas dentro dos grupos formados

\begin{tabular}{|c|c|c|c|c|c|c|c|}
\hline Grupo 1 & \begin{tabular}{|l} 
Fator \\
Aquisições
\end{tabular} & $\begin{array}{l}\text { Fator } \\
\text { Eficiência }\end{array}$ & Fator Escopo & \begin{tabular}{|l|} 
Fator Comu- \\
nicação
\end{tabular} & Fator Riscos & $\begin{array}{l}\text { Fator } \\
\text { Qualidade }\end{array}$ & $\begin{array}{l}\text { Fator } \\
\text { Integração }\end{array}$ \\
\hline Fator Aquisições & & Sig & sig & - & - & - & - \\
\hline Fator Eficiência & Sig & & sig & sig & sig & sig & Sig \\
\hline Fator Escopo & Sig & Sig & & - & sig & sig & - \\
\hline Fator Comunicação & - & Sig & - & & - & - & - \\
\hline Fator Riscos & - & sig & sig & - & & - & - \\
\hline Fator Qualidade & - & sig & sig & - & - & & \\
\hline Fator Integração & - & sig & - & - & - & - & \\
\hline Grupo 2 & \begin{tabular}{|l} 
Fator \\
Aquisições
\end{tabular} & $\begin{array}{l}\text { Fator } \\
\text { Eficiência }\end{array}$ & Fator Escopo & $\begin{array}{l}\text { Fator Comu- } \\
\text { nicação }\end{array}$ & Fator Riscos & $\begin{array}{l}\text { Fator } \\
\text { Qualidade }\end{array}$ & \begin{tabular}{|l} 
Fator \\
Integração
\end{tabular} \\
\hline Fator Aquisições & & & sig & & & & \\
\hline Fator Eficiência & & & sig & sig & sig & & \\
\hline Fator Escopo & sig & sig & & & & Sig & sig \\
\hline Fator Comunicação & & sig & & & & & \\
\hline Fator Riscos & & sig & & & & & Sig \\
\hline Fator Qualidade & & & sig & & & & \\
\hline Fator Integração & & & sig & & sig & & \\
\hline Grupo 3 & \begin{tabular}{|l} 
Fator \\
Aquisições
\end{tabular} & \begin{tabular}{|l} 
Fator \\
Eficiência
\end{tabular} & Fator Escopo & $\begin{array}{l}\text { Fator Comu- } \\
\text { nicação }\end{array}$ & Fator Riscos & $\begin{array}{l}\text { Fator } \\
\text { Qualidade }\end{array}$ & \begin{tabular}{|l} 
Fator \\
Integração
\end{tabular} \\
\hline Fator Aquisições & & sig & sig & & & & \\
\hline Fator Eficiência & sig & & & Sig & & sig & sig \\
\hline Fator Escopo & sig & & & & & sig & sig \\
\hline Fator Comunicação & & sig & & & & & sig \\
\hline Fator Riscos & & & & & & & sig \\
\hline Fator Qualidade & & sig & sig & & & & \\
\hline Fator Integração & & sig & sig & sig & sig & & \\
\hline Grupo 4 & \begin{tabular}{|l|} 
Fator \\
Aquisições
\end{tabular} & \begin{tabular}{|l|} 
Fator \\
Eficiência \\
\end{tabular} & Fator Escopo & \begin{tabular}{|l|} 
Fator Comu- \\
nicação
\end{tabular} & Fator Riscos & \begin{tabular}{|l} 
Fator \\
Qualidade
\end{tabular} & \begin{tabular}{|l} 
Fator \\
Integração
\end{tabular} \\
\hline Fator Aquisições & & & Sig & & & & \\
\hline Fator Eficiência & & & Sig & & & sig & \\
\hline Fator Escopo & sig & sig & & sig & sig & sig & sig \\
\hline Fator Comunicação & & & Sig & & & sig & \\
\hline Fator Riscos & & & Sig & & & & \\
\hline Fator Qualidade & & sig & sig & sig & & & \\
\hline Fator Integração & & & sig & & & sig & \\
\hline
\end{tabular}

Obs: Onde existe diferença estatisticamente significante ao nível de 5\% entre o os valores médios dos fatores está destacado com "sig".

Para complementar a análise e caracterização dos grupos formados, foi feita uma tabulação do setor de atividade das empresas em cada grupo (Tabela 6). Nem todos informaram a área de atuação o que causou a diferençado número de observações. 
Tabela 6 - composiçãodos grupos

\begin{tabular}{|c|c|c|c|c|c|}
\hline \multirow{2}{*}{ Setor } & \multicolumn{4}{|c|}{ Grupos de Maturidade } & \multirow{2}{*}{ Total } \\
\hline & 1 & 2 & 3 & 4 & \\
\hline Fábrica & 3 & 1 & 1 & 4 & 9 \\
\hline $\mathrm{TI}$ & 9 & 22 & 7 & 5 & 43 \\
\hline Bancos & 2 & 4 & 2 & 1 & 9 \\
\hline Serviços & 1 & 4 & 5 & 2 & 12 \\
\hline Assoc de Classe & 0 & 0 & 0 & 1 & 1 \\
\hline Comércio & 0 & 0 & 2 & 0 & 2 \\
\hline Total: & 15 & 31 & 17 & 13 & 76 \\
\hline
\end{tabular}

O grupo 1 (Foco na eficiência) tem sua atenção voltada ao sucesso de curto prazo do projeto. Nestas organizações há uma maior formalização dos processos relacionados à observância de prazos e custos, além de focar atingir metas e especificações de qualidade. Esta situação é facilmente relacionada a uma visão clássica, porém limitada, de sucesso de projetos (BAKER, FISHER e MURPHY, 1983). Indicadores de produtividade mediriam, tipicamente, o uso de recursos (eficiência), como por exemplo, quantidade gasta de homens-hora. Embora alguns estudos tenham enfatizado a predominância desta abordagem em empresas classificadas no quadrante "Suporte" do grid estratégico de McFarlan (1984), não é possível afirmar que a TI, em particular os SI, não seja importante para estas empresas incluídas no grupo 1.

O grupo 2 (Foco no escopo) é o que apresenta maior maturidade nas dimensões Escopo, Comunicação e Risco. Nas outras dimensões apresenta um grau mediano de maturidade. Isto indica que são organizações que tentam manter um equilíbrio entre os vários processos da gestão de projetos. Ao contrário do que acontece no grupo $4, \mathrm{o}$ interesse na gestão do escopo não é feito à revelia da gestão dos riscos e da qualidade do projeto.

Nestas organizações, aparentemente, existe uma preocupação maior com os aspectos da gestão de projetos que tendem a ter maior influência nas dimensões de médio e longo prazo do desempenho do projeto. Ou, pelo menos, naqueles relacionados como que Shenhar (2001) chama de Impacto no Consumidor (desempenho funcional, conformidade às especificações técnicas, preenchimento das necessidades do cliente, resolução dos problemas do cliente, uso do produto pelo cliente e satisfação do cliente). Estas empresas têm uma atenção menor à eficiência do projeto (custo e prazo), porém dão mais atenção a gestão do escopo, dos riscos e das comunicações.

Isto pode ser interpretado com uma preocupação maior em aspectos do desempenho dos projetos de médio e longo prazo (no modelo de Senhar) ou aspectos externos no modelo de Pinto e Slevin_(1988): o uso do produto gerado, atendimento das necessidades dos usuários e a satisfação dos usuários. A atenção dada à gestão das comunicações pode ser interpretada como reconhecimento da importância da relação com os usuários do produto do projeto. A gestão do escopo estaria relacionada com a gestão das mudanças de requisitos no projeto de forma a atender adequadamente às necessidades dos usuários, isto é, resolver os problemas (atender às necessidades) que estão por trás do SI em desenvolvimento.

A principal característica do grupo 3 (Foco na integração) é o alto nível obtido na dimensão Integração, superior ao de todos os demais grupos. Há uma indicação, ainda que sem prova estatística, que isto possa estar relacionado com o processo de aquisição. Organizações que adquirem de diversos fornecedores precisam, principalmente em projetos de SI, de esforços especiais em termos de integração.

Isto parece corresponder às organizações que desenvolvem projetos com múltiplas interfaces com outros sistemas. Organizações que possuem uma grande quantidade de sistemas legados enfrentam o desafio da integração de diferentes arquiteturas e plataformas. Nestas condições, um novo projeto tende a criar uma necessidade de mudança (manutenção) nem sistemas já implantados, um processo de controle integrado de mudanças tem importância vital no desempenho destes projetos. 
Desta forma, este grupo refere-se a organizações que dão grande a gestão da qualidade e a gestão integrada, mas muita pouca atenção, em termos relativos, a questão do escopo e da eficiência. Isto pode ser interpretado como um momento de transição quando a empresa reconhece a importância dos projetos de sistemas de informação e busca competências externas para sua realização, e a gestão da integração exerceria um papel crucial de elemento de captação destas novas competências.

No Grupo 4 (Empresas “despreocupadas"), nota-se que, embora haja alguma atenção ao escopo, as empresas prestam pouca atenção à qualidade, menor atenção aos riscos (menor que os grupos 1 e 2) e menor atenção que o grupo 1 à comunicação. Processos de aquisições, comunicações, riscos, qualidade e integração são menos formalizados e, portanto, imaturos.

Este último grupo parece corresponder às organizações em que a correta e completa implantação de todos os elementos e partes do projeto inicial é condição essencial para o sucesso do projeto. Nestas condições, a gestão do escopo ganha destacada relevância em relação às demais dimensões.

Organizações que desenvolvem principalmente projetos com características obrigatórias, que Farbey et al. (1995) chamam de projetos obrigatórios, se encaixam neste grupo. São projetos que

implementam, em grande parte, aspectos legais como sistema de escrituração ou folha de pagamento. Não há outra alternativa a não ser implementar o sistema, em especial quando não há muito tempo disponível.

\section{Considerações finais}

O comportamento da maturidade em gestão de processos nas organizações estudadas não segue uma distribuição "de escada", uma evolução unidimensional, como propõem os modelos de maturidade. Pelo contrário, os resultados sugerem uma visão multidimensional da maturidade em que os processos de gestão se relacionam com estas as dimensões da maturidade. A análise fatorial mostrou que a maioria desses processos tende a se relacionar mais fortemente com uma das dimensões, apenas os processos de gestão de recursos humanos se "diluíram" entre estes processos.

A análise de clusters sugere que o perfil de maturidade desejado, em função das diferentes dimensões da maturidade, não é o mesmo para as organizações. A necessidade uma maior maturidade em dimensões específicas, explicaria a construção dos diferentes grupos gerados.

Assim, é importante que os profissionais da área de gestão de projetos entendam as particularidades de seu contexto para poderem identificar a forma pela qual a maturidade em gestão de projetos deve ser buscada - quais dimensões são mais relevantes.

Como possível desdobramento para pesquisas posteriores, poderia ser buscada uma melhor compreensão da relação das dimensões da maturidade com as características do meio ambiente. Isto permitiria a construção de modelos contingenciais de estudo da maturidade em gestão de projetos.

Embora o presente trabalho ainda seja uma pesquisa inicial, passível de aprimoramento e desdobramentos, algumas conclusões podem ser observadas.

O foco de curto prazo, cada vez mais freqüente diante da realidade competitiva que as empresas enfrentam, leva a uma visão que privilegia a eficiência, o que pode ser percebida pelo comportamento das respostas acerca de gestão de custos e de prazos.

Neste mesmo contexto, a disseminação do conhecimento é fator de vantagem competitiva, o que é refletido na distribuição dos fatores relativos aos recursos humanos ao longo de todas as dimensões. $\mathrm{O}$ fator humano mostra-se um importante vetor da transmissão do conhecimento. Finalmente, a pesquisa leva a uma reflexão acerca do conceito de maturidade em projetos.

Os grupos formados evidenciam que maturidade não caminha de forma unidimensional, ao contrário do que sugere a grande maioria dos modelos de maturidade de gesto de projeto que estão sendo propostos. 
As conclusões aqui apresentadas baseiam-se na amostra pesquisada, o que implica em cautela em eventuais tentativas de generalização das conclusões. Deve-se lembrar aqui que amostra deste estudo foi intencional, o que não permite a generalização de seus resultados. Isto, contudo, numa pesquisa de caráter exploratório como esta, deve ser entendida mais como uma característica do que uma limitação. Futuras pesquisas deverão explorar e analisar estes pontos acima mencionados.

\section{Referências}

ANTONIONI, L. ROSA, N. B. Qualidade em software; manual de aplicação da ISO 9000. São Paulo: Makron Books. 1995.

BACCARINI, D. (The Logical Framework Method for Defining Project Success : International Journal of Project Management, vol. 30, no. 4, p. 25-32, 1999.

BAKER, Bruce N., MURPHY, David C. e FISHER, Dalmar (1983) Factors Affecting Project Success. In CLELAND, D. I.; KING, W. R. Systems analysis and Project management. New York: McGraw Hill.

CLELAND, D. I; IRELAND, L. R. Gerência de Projetos . Rio de Janeiro: Reichmann \& Affonso Editores, 2002.

FARBEY, B.; LAND, F. F.; TARGETT, D. A taxonomy of information systems applications: the benefits evaluation ladder. European Journal of Information Systems, v.4, n.1, p.41-50. 1995.

FINCHER, A.; LEVIN, G. Project Management Maturity Model. Project Management Institute 28th Annual Seminar/Symposium, Chicago, Ill., p. 48-55. 1997.

GOLDSMITH, L. Approaches Towards Effective Project Management, Project Management Maturity Model. Project Management Institute 28th Annual Seminar/Symposium, Chicago, Ill., 1997. p. 49-54. 1997.

HAIR JR., J. F. et al.1. - Multivariate Data Analysis - New York, Macmilan Publishing Company. 1998.

HARTMAN, F. T.; SKULMOSKI, G. Project Management Maturity. Project Management Journal, p. 74-78. 1998.

IBBS, W. and KWAK, Y.H. The Benefits Of Project Management: Financial and Organizational Rewards to Corporations. Project Management Institute. Sylvia, N.C. 1997.

IBBS, W.; KWAK, Y.H. Assessing Project Management Maturity. Project Management Journal, vol. 31, no. 1, pp. 32-43, Mar. 2000.

KALANTJAKOSN. J. Assessing Organizational Project Management Maturity. Proceedings of the Project Management Institute Annual Seminars \& Symposium, USA: Nashville, Tennessee, Nov. 2001.

MCFARLAN, W.E. Information Technology Changes The Way You Compete. Harvard Business Review, v.62, n.3, p.98-103, May/June. 1984.

McGRATH, M. E. Revving up product development. In: Electronic Business Magazine, january 1998, p. 36

MORAES, R. O. Condicionantes de desempenho dos projetos de software e a influência da maturidade em Gestão de Projetos, Tese de doutorado. FEA/USP. São Paulo. 2004.

PINTO, J. K.; SLEVIN, D. P. Project Success : Definitions and Measurement Techniques International Journal of Project Management. 1988.

PMBOK A guide to the project management body of knowledge PMI- Project Management Institute. 2000.

REMY, R. Adding focus to improvement efforts with PM3.PM Network, July. 1997.

ROBIC, A. R.; SBRAGIA, R. Sucesso em Projetos de Informatização: critérios de avaliação e fatores condicionantes, Economia \& Empresa, vol. 2, no. 3, p. 4-16, jul/set. 1995. 
SHENHAR, A. et al.1. Project success: a multidimensional strategic concept. Long Range Planning, no. 34, pp. 699-725. 2001.

SCHLICHTER, J. PMI's Organizational Project Management Maturity Model: Emerging Standards. Proceedings of the Project Management Institute Annual Seminars \& Symposium, USA: Nashville, Tennessee, Nov. 2001.

\section{ANEXO I - Dendograma}

\section{Rescaled Distance Cluster Combine}

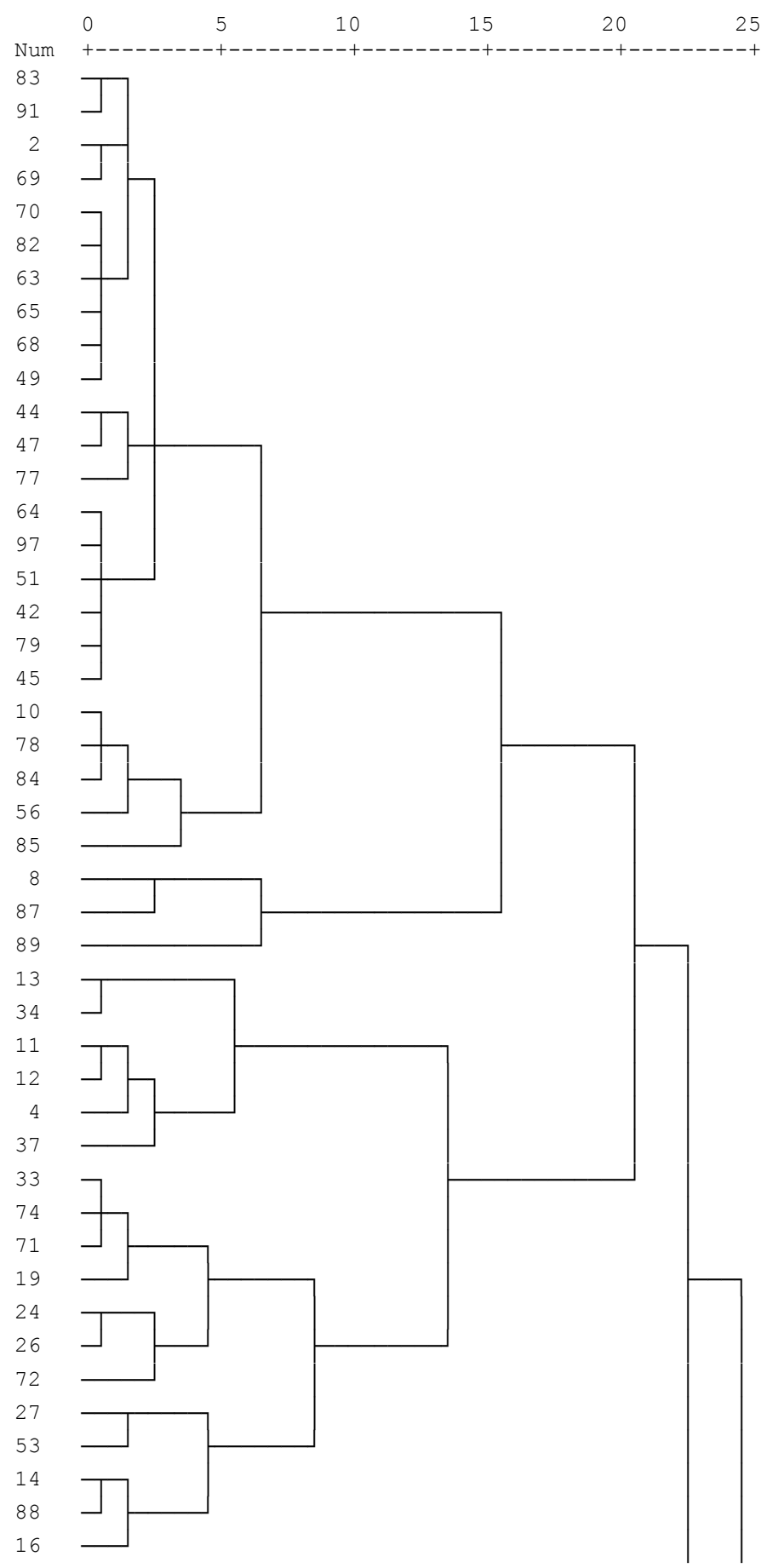




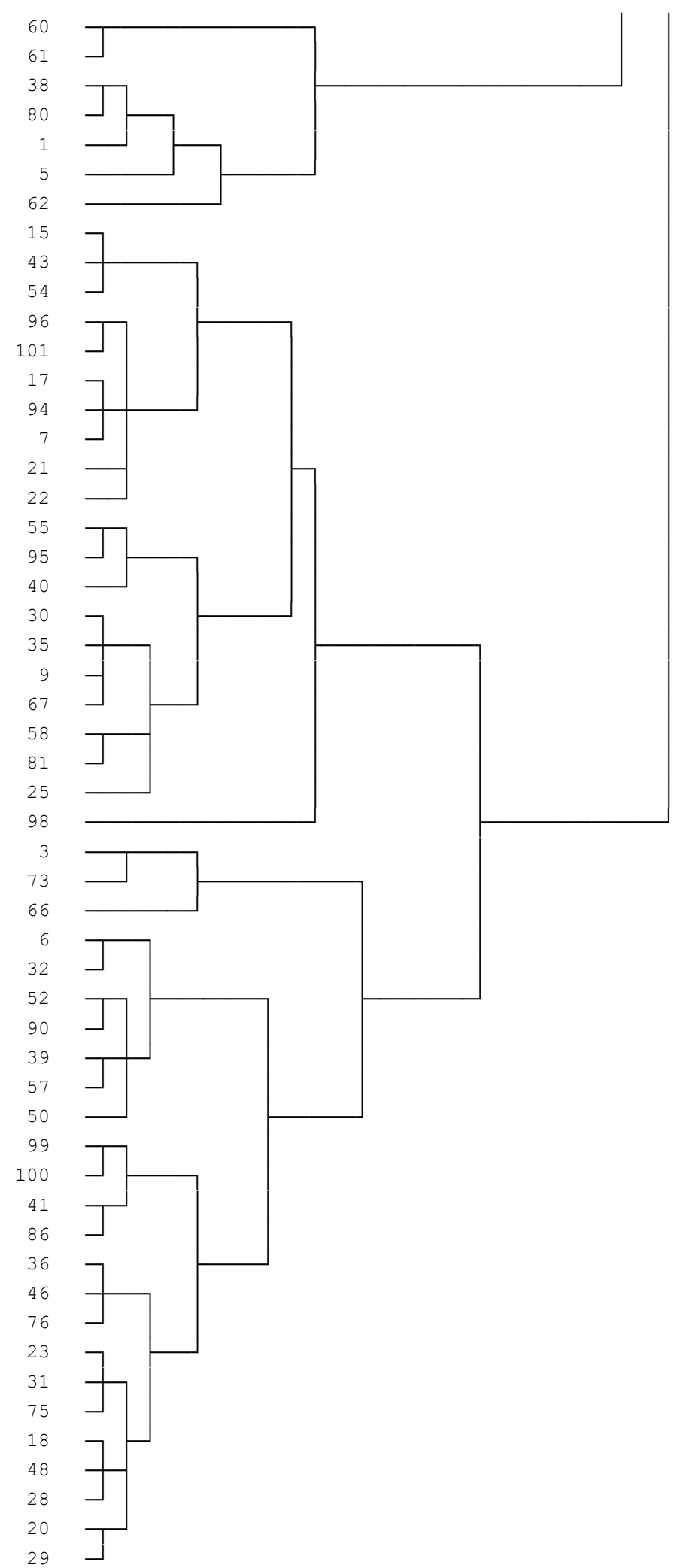

